NOTE

\title{
Binding of Organic Solutes to a Polymer Containing Pendant Sugar Groups
}

\author{
Kazukiyo Kobayashi and Hiroshi Sumitomo \\ Faculty of Agriculture, Nagoya University, \\ Furo-cho, Chikusa-ku, Nagoya 464, Japan.
}

(Received November 13, 1980)

\begin{abstract}
KEY WORDS Amphiphilic Polymer / Sugar-Containing Polymer / 1Anilino-8-naphthalenesulfonate (ANS) / Fluorescence / Binding / Hydrophobic Interaction /
\end{abstract}

Polymers containing sugars as pendant groups are receiving a growing amount of attention because of the possibility for their use in a wide range of applications for which natural polysaccharides are not suitable. Several types of sugar-containing polymers have been developed in order to make use of hydrophilicity, ${ }^{1,2}$ chirality, ${ }^{3,4}$ and biological activity $^{5,6}$ of sugars. From this standpoint, we synthesized an amphiphilic polymer $\mathbf{2}$, from glucose and chloromethylstyrene as starting materials. ${ }^{7}$ The

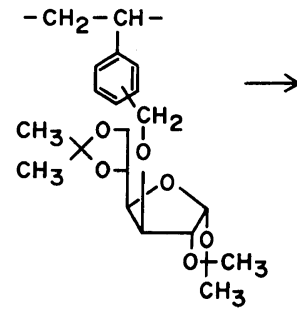

1

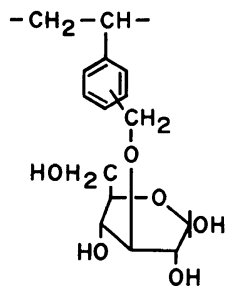

2
Scheme

solution properties of $\mathbf{2}$ suggested that it behaved as a nonionic polysoap in water, and a spectrophotometric investigation showed that an organic solute such as methyl orange was strongly bound to the hydrophobic regions of $\mathbf{2}$ in water.

The present study was undertaken in order to confirm the solute binding properties of $\mathbf{2}$ using magnesium 1-anilino-8-naphthalenesulfonate (ANS) as the organic solute. ANS has been used extensively as a hydrophobic probe, that is nonfluorescent in water but becomes highly fluorescent on binding to non-polar regions in proteins, ${ }^{8,9}$ biomembranes, ${ }^{10}$ cyclodextrins, ${ }^{11-13}$ and synthetic polymers. ${ }^{14}$ The ANS binding constants of 2 were determined and compared with those of analogs.

\section{EXPERIMENTAL}

Polymer 2 used was prepared from its precursor 1 with a number-average degree of polymerization of $420 .^{7}$ ANS, supplied by Nakarai Chemicals, Ltd., was recrystallized twice from hot water. Fluorescence spectra were recorded with a JASCO FP550 spectrofluorometer at room temperature. The excitation wavelength was $380 \mathrm{~nm}$ and both the excitation and emission slits were set at $10 \mathrm{~nm}$.

\section{RESULTS AND DISCUSSION}

Figure 1 depicts fluorescence emission spectra of ANS in the absence and presence of the polymer 2. Fluorescence of ANS alone was negligible, but $\mathbf{2}$ induced a striking enhancement of the fluorescence. Simultaneously, the emission maximum $\lambda_{\max }^{\mathrm{F}}$ also blue-shifted; it decreased abruptly with increasing polymer concentrations and took on a constant value $(475 \mathrm{~nm})$ at polymer concentrations higher than $10^{-3} \mathrm{M}$. The large blue shift by $50 \mathrm{~nm}$ on binding to 2 indicates that the bound ANS remained in a hydrophobic microenvironment. It is suggested that the emission maximum of the adsorb- 


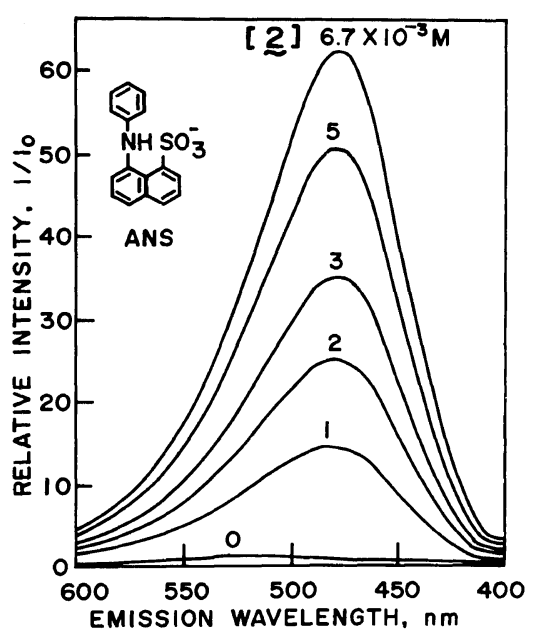

Figure 1. Fluorescence emission spectra of ANS in the presence of 2 : [ANS], $5 \times 10^{-5} \mathrm{M}$; [2], $0 \sim 6.7 \times 10^{-3} \mathrm{M}$; solvent, phosphate buffer ( $\mathrm{pH}$ 6.88).

ed probes may be regarded as a measure of solvent polarity. ${ }^{8,15}$ In this respect, the present system had a solvent polarity similar to those of methanol $\left(\lambda_{\max }^{\mathrm{F}}\right.$, $476 \mathrm{~nm})$ and an ethanol-water $(90: 10 \mathrm{v} / \mathrm{v})$ mixture $\left(\lambda_{\max }^{\mathrm{F}}, 477 \mathrm{~nm}\right){ }^{8}$ For the following quantitative treatments, the polymer and ANS concentrations ranged from $10^{-3}$ to $10^{-2} \mathrm{M}$ and from $10^{-5}$ to $5 \times 10^{-5} \mathrm{M}$, respectively.

The relative fluorescence intensity $\left(I / I_{0}\right)$ was evaluated in the form of the Benesi-Hildebrand equation, ${ }^{16}$

$$
\frac{[\mathrm{ANS}]}{I / I_{0}}=\frac{1}{[2]} \times \frac{1}{K^{\prime}\left(I_{\infty} / I_{0}\right)}+\frac{1}{I_{\infty} / I_{0}}
$$

where $I_{\infty} / I_{0}$ is the actual relative fluorescence of the bound ANS and $K^{\prime}$ is the binding constant. As Figure 2 illustrates, the Benesi-Hildebrand relationship yielded a straight line for each ANS concentration. Each intercept and slope gave a value of 125 for $I_{\infty} / I_{0}$ and $120 \mathrm{M}^{-1}$ for $K^{\prime}$, respectively. The agreement of these values among the three series was fairly good.

Since the observed fluorescence was attributable only to the bound ANS, its concentration ([ANS $]_{\mathrm{B}}$ ) could be estimated by eq 2 , and then the free ANS concentration $\left([\mathrm{ANS}]_{\mathrm{F}}\right.$ ) by eq 3 .

$$
\begin{aligned}
& {[\mathrm{ANS}]_{\mathrm{B}}=[\mathrm{ANS}] \times\left(I / I_{0}\right) / 125} \\
& {[\mathrm{ANS}]_{\mathrm{F}}=[\mathrm{ANS}]-[\mathrm{ANS}]_{\mathrm{B}}}
\end{aligned}
$$

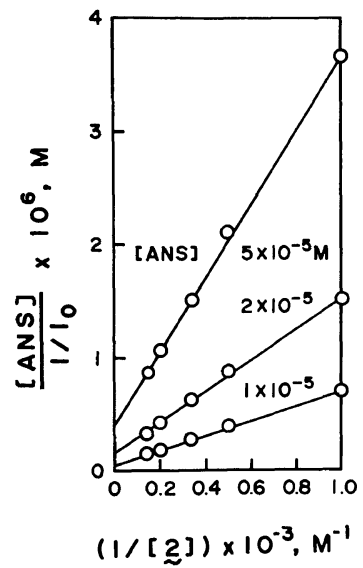

Figure 2. Benesi-Hildebrand relationship for binding of ANS to 2 .

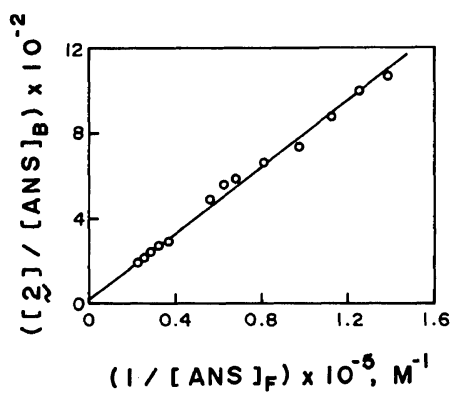

Figure 3. Klotz relationship for binding of ANS to 2 .

A rearranged form of the Langmuir isotherm suggested by Klotz (eq 4$)^{17}$ is now applicable to the present system.

$$
\frac{[2]}{[\mathrm{ANS}]_{\mathrm{B}}}=\frac{1}{[\mathrm{ANS}]_{\mathrm{F}}} \times \frac{1}{K n}+\frac{1}{n}
$$

The constant $1 / n$ denotes the minimum number of structural units required to bind a solute molecule and $K$ is the intrinsic binding constant, while the product $K n$ is the first binding constant. As shown in Figure 3, the plot of $[2] /[\mathrm{ANS}]_{\mathrm{B}}$ vs. $1 /[\mathrm{ANS}]_{\mathrm{F}}$ is linear. The $K n$ calculated from the slope was $130 \mathrm{M}^{-1}$, which agrees closely with the $K^{\prime}$ obtained from the Benesi-Hildebrand relationship. The intercept on the ordinate axis corresponded to a $1 / n$ of 20 , yielding a $K$ of $2600 \mathrm{M}^{-1}$. These constants are comparable to the methyl orange binding constants of 2 previously reported. ${ }^{7}$ Evidently polymer 2 bound to ANS more strongly than to methyl orange, while the size of the binding site $(1 / n)$ of 
2 did not change.

Water soluble nonionic polymers such as poly(vinyl alcohol), dextran, and starch exhibited no interaction with ANS. On the other hand, poly(vinylpyrrolidone) was reported to interact hydrophobically with ANS, ${ }^{14}$ although its binding constant is not presented in the literature as far as we know. Among other nonionic polymers, cyclodextrins are interesting for comparison since both 2 and cyclodextrins are made up of carbohydrates. The ANS binding constant of $\beta$-cyclodextrin estimated by the Benesi-Hildebrand method was $56 \mathrm{M}^{-1}$. ${ }^{i 1}$ That is, the binding constant of 2 was about twice that of $\beta$-cyclodextrin. A better comparison of binding strength should be done with use of binding constants based on a unit weight. Thus, a constant $K^{*}$ expressed in units per $10^{5} \mathrm{~g}$ of polymer has been frequently used in the literature. ${ }^{17,18}$ The reduced $K^{*}$ was $4.1 \times 10^{4}$ for 2 and $0.49 \times 10^{4}$ for $\beta$ cyclodextrin, indicating that 2 was about 8 times more effective in binding to ANS than $\beta$-cyclodextrin was. In these respects, the binding strength of 2 was closer to those of hydrophobically capped $\beta$ cyclodextrins, ${ }^{12}$ although polymers containing $\beta$ cyclodextrin as pendant groups were superior. ${ }^{13}$

Needless to say, these cyclodextrins each have an inclusion cavity of hydrophobic character, but $\mathbf{2}$ does not. Charged groups, long methylene chains, and cross-linkings are also known to enhance the solute binding properties of certain polymers, but 2 has none of these structural characteristics. Nevertheless, 2 has a strong affinity for organic solutes in water. As pointed out in the previous paper, ${ }^{7}$ it seems reasonable to assume that the solute binding sites of $\mathbf{2}$ were formed by the hydrophobic aggregation of the vinylbenzyl residues enclosed in the hydrophilic surroundings consisting of water-solvated sugar moieties.

Thus, we may say that polymer 2 consisting of sugar and styrene derivatives, is a new type of amphiphilic polymer which has strong solute binding properties in water.

\section{REFERENCES}

1. G. Maconochie, A. Sharples, and G. Thompson, Eur. Polym. J., 7, 499 (1971).

2. K. Kobayashi and H. Sumitomo, Polym. Bull., 1, 121 (1978).

3. M. Kawana and S. Emoto, Tetrahedron Lett., 4855 (1972).

4. G. Wulff and W. Vesper, J. Chromatogr., 167, 171 (1978).

5. B. Helferich and K.-H. Jung, Z. Physiol. Chem., 311, 54 (1958).

6. L. A. Carpino, H. Ringsdorf, and H. Ritter, Makromol. Chem., 177, 1631 (1976).

7. K. Kobayashi and H. Sumitomo, Macromolecules, 13, 234 (1980); K. Kobayashi and H. Sumitomo, Nippon Kagaku Kaishi, 406 (1980).

8. L. Stryer, J. Mol. Biol., 13, 482 (1965).

9. L. Stryer, Science, 162, 526 (1968).

10. L. Brand and J. R. Gohlke, Ann. Rev. Biochem., 41, 843 (1972).

11. F. Cramer, W. Saenger, and H. Ch-Spatz, J. Am. Chem. Soc., 89, 14 (1967).

12. I. Tabushi, K. Shimokawa, N. Shimizu, H. Shirakata, and K. Fujita, J. Am. Chem. Soc., 98, 7855 (1976).

13. A. Harada, M. Furue, and S. Nozakura, Makromolecules, 10, 676 (1977).

14. Y. E. Kirsh, T. A. Soos, and T. M. Karputadze, Eur. Polym. J., 15, 223 (1979).

15. D. C. Turner and L. Brand, Biochemistry, 7, 3381 (1968).

16. H. A. Benesi and J. H. Hildebrand, J. Am. Chem. Soc., 71, 2703 (1949).

17. I. M. Klotz, F. M. Walker, and R. B. Pivan, J. Am. Chem. Soc., 68, 1486 (1946).

18. R. Sinta and J. Smid, Macromolecules, 13, 339 (1980). 